\title{
Medication labeling literacy among Malaysian with diabetes: a cross-sectional study
}

\author{
Norhafizah $\mathrm{S}^{1 *}$, Siti Zuraidah $\mathrm{M}^{1}$, Riyanti S ${ }^{1}$, Balkish M.N ${ }^{1}$, Hamizatul Akmal A. $\mathrm{H}^{1}$ and Hatta $\mathrm{M}^{1}$ \\ *Correspondence: norhafizah_s@iku.moh.gov.my \\ ${ }^{1}$ Institute for Public Health, National of Health, Ministry of Health Malaysia.
}

\begin{abstract}
Background: Medication labeling provides valuable health information for diabetes patients. Study on medication labeling literacy among diabetic population in Malaysia has never been done before. Therefore, this study was conducted to assess health literacy among Malaysian diabetes population on medication labeling.

Methodology: Secondary data from National Health and Morbidity Survey 2006 was used. It was a cross sectional study using a stratified two stage sampling technique. The data was analyzed using SPSS version 18 . Descriptive and multiple logistic regressions were used in the analysis. All tests were two tailed with significance as $\mathrm{p}<0.05$. Odds ratio (OR) along with 95\% confidence level (C.I) were derived where appropriate.

Results: There were 3851 eligible respondents in this study. The prevalence of diabetes patients who read medication labels were $75.3 \%$ (95\% CI: 73.8, 76.6), did not read the label every time they received or bought medicine, 9.9\% (95\% CI: 18.6,21.2) and 4.8\% (95\% C.I: 4.1,5.6) were refuse to answer. Elderly, no formal education background and Chinese ethnic group were significantly lower in prevalence of reading medication label. Most of the respondents read information such as dosage; (46.40\%), method of administration; (42.20\%) and frequency of intake (40.80\%). Only 8 respondents were found to read all the eight types of information on the medication labels. Majority of the respondents, $97.1 \%$ (95\%CI: 96.4,97.7) claimed they understood the medication label information. Respondents who claimed they did not understand medication label were those without any formal education; 7.9\% (95\%C.I: 4.8,12.9), and elderly of 70 years and above; $4.3 \%$ (95\%CI: 1.9, 9.3). Twelve percent of respondents never sought for clarification from the dispenser/pharmacist about their medicines. The highest prevalence of respondents who did not asked for clarification from dispenser/pharmacist were those with no formal education $14.7 \%$ (95\% C.I: $1.7,2.6)$ and elderly aged 70 years and above; $16.0 \%$ (95\% CI:12.4, 20.4).
\end{abstract}

Conclusion: Key strategies for health education towards medical labeling literacy among Malaysian diabetes need to be developed and be implemented accordingly.

Keywords: National Health and Morbidity Survey, NHMS, diabetes, medication label, health literacy

\section{Introduction}

Health literacy is "the degree to which individuals have the capacity to obtain process and understand basic health information and services to make an appropriate health decisions". This includes the ability to read and comprehend prescription bottles, appointment slips and other essential health-related materials that must be understood to function successfully as a patient [1]. Individuals with adequate health literacy skills will have capabilities to access and pay for medical care; understand health care advice; follow recommendations for treatment; practice safe and correct use of medicine; think of the risk and benefits of health decisions; and understand rights and responsibilities in health care [2]. Research has shown, patients with inadequate health literacy have a poorer health status, less knowledge about their disease and the treatments, less in health self-management skills, increased hospitalizations, increase health costs and have poorer adherence rates [3].

Elsewhere, others have found that half of the Australian and New Zealanders have low health literacy skills that could interfere with their health and medical care. Elderly Australians were found to have lower health literacy in comparison to other groups in the population. New Zealanders with tertiary education level are more likely to have good literacy skills compared to those with lower education levels [4].

The United States of America undertook the National Assessment of Adult Literacy (NAAL) in 2003. It was found that over a third of U.S adults have difficulty with common health task such as following directions on a prescribed drug label or adhering to a child immunization schedule using a standard chart. Limited health literacy affects adults in all racial and ethnic groups. Forty million U.S.

(C) 2012 Norhafizah et al; licensee Herbert Publications Ltd. This is an open access article distributed under the terms of Creative Commons Attribution License (http://creativecommons.org/licenses/by/3.0),This permits unrestricted use, distribution, and reproduction in any medium, provided the original work is properly cited. 
adults are reading at the lowest levels of literacy proficiency and may have profound difficulty of understanding health information for their own or a loved one's needs [5]. About half of Americans have difficulty reading and using health information in their daily life; therefore poor health literacy is a critical barrier towards achieving adequate care [6]. Low health literacy and numeracy affecting approximately one in three Americans adults and they are associated with poor health outcomes across chronic disease contexts [7].

In Malaysia, a population based survey was conducted to access the health literacy on medication and nutritional labeling. It was found that few people really read and understood nutritional information in nutritional labeling. Expiry date was the most being read. Majority of the respondents (61.1\%) claimed to read medication label but it was not a common practice to the other $16 \%$. Those with higher education and holding higher positions have better understanding on medications labeling and tended to know more about their medications [8].

Understanding of medication labels is imperative to avoid medication error and related adverse events. Medication label was formulated to be guidance for the users to know its ingredients, dosage, expiry date, method for storage and adverse effects. Under the Malaysian Poison Regulation 1952, seven elements have been identified as the standard for labeling dispensed medication. The label must have the name and address of the supplier or seller; the name of patients or purchaser; the name of medicine; adequate directions for the use of such medicine; the date of delivery of such medicine; and where such medicine is sold or supplied and entered in a prescription book detailing reference to the serial number of the entry in such book relating to such sale or supply.

Individuals that unable to read were at particular risk for misunderstanding information on pharmaceutical drug labels and package inserts, thus misusing these medications [9]. Diabetes patients with low health literacy have greater difficulty understanding their disease $[10,11]$ participate less in self-care activities and have poorer glycemic control [12]. Study on medication labeling literacy among Malaysian diabetic population has never been done before. Therefore, this study was conducted to assess health literacy among Malaysian diabetic population towards medication labeling.

\section{Materials and Method The third National Health and Morbidity Survey (NHMSIII,2006)}

The NHMS 2006 is a national survey and uses a sampling frame of the Malaysian department of Statistics. The country is divided into contiguous geographical areas called Enumeration Blocks (EBs). These EBs constituted the sampling frame for the NHMS 2006. A two stage stratified sample design was used. The first stage sampling unit was the $E B$ and the second stage sampling unit was the
Living Quarters (LQ). All household and persons within a selected LQ were included in the survey. The EBs were selected using a probability which was proportionate to a size linear systematic selection scheme based on the latest updated size measurement. The selection of EBs was carried out independently within each state (as a primary stratum) and within urban or rural areas (as secondary stratum) in accordance with the selection rate determined for each stratum. This ensured that the sample size was representative of the population national levels.

Field data collection was conducted for four months in 2006. A bi-lingual (Malay and English) pre-coded questionnaire was designed, pre-tested and piloted prior to the administration of the survey. Trained research assistant conducted face-to-face interviews with parents or guardians of children. The complete protocol can be found elsewhere [6].

\section{Sampling}

All confirm diabetic respondent age 18 years and above were selected for the purpose of this study. Diabetes respondents were determined by two specific criteria. The known diabetes was by self-administered of respondents and for those who claimed were not diabetic underwent finger-prick glucose test following at 8 hours of fasting. Respondents were classified as diabetes when glucose level was equal to or more than $6.1 \mathrm{mmol} / \mathrm{L}$.

\section{Instrument}

The questions on medication labeling were subjected to all eligible respondents (18 years and above). For the purpose of this study, eligible respondents include all confirmed diabetic respondents whom answered a survey instrument from the medication labeling module. The medication labeling module contains four questions that cover on the aspect of reading label, types of information on label reading, understanding medication label and clarification on medication labels.

For the reading label, respondents were asked if they ever read their medication label at every time they received or bought their medicine with a possible one categorical answer (1) =Yes, (2) =Never and (3)=Refuse to answer. For types of information on label reading, respondents were asked on types of information on the medication label that they read includes possible multiple categorical answer (1) =Registration number, (2) =Name of medicine(3) =Purpose, (4) $=$ Dosage $(5)=$ Frequency, $(6)=$ How to use/take (7) =Expiry date, and (8)=Storage conditions. Respondents were also asked about their understanding pertaining to information on the medical label with a possible categorical answer (1) =Yes, (2) =Never and (3) =Refuse to answer. Question on clarification practice was asked whether respondents ever initiate to get clarification about their medicine that they received or bought from dispenser with a possible categorical answer (1) =Yes, (2) =Never and (3) = Refuse 
to answer.

Data was collected through face to face interview by trained data collectors using structured questionnaires.

\section{Data analysis}

Data analyses were conducted using SPSS version 18.0 with a complex survey design. Descriptive analyses were conducted for socio-demographic characteristics included residency, gender, age, race, and education level. Bivariate analyses were calculated to estimate the prevalence of reading label, types of information on label reading, understanding medication label and clarification on medication labels by the socio-demography profiles.

A multiple logistic regression modeling was applied to analyze the odds of understanding the medication label by the socio-demographic predictors for residency, gender, race, age group and education level. Final model is created that will include all predictors and interactions which were significantly associated at a level of $p$-value $<0.05 \%$.

\section{Results}

Socio-demographic Characteristics of respondent A total of 3851 adults were included in this study with the estimated of 1,492,665 diabetic population in Malaysia. More than half of them (63\%) resided in urban areas than $37 \%$ in rural areas. About $54 \%$ of the respondents were females and $46 \%$ were males. Ethnic breakdown comprises of $57 \%$ Malays, $21 \%$ Chinese, $14 \%$ Indians, $6 \%$ other local minority ethnic while $2 \%$ other ethnicity as described. The median of age group in this sample population is 52.3 where majority of respondents were among those at age of 50 - 59 years old (32\%), followed by $40-49$ years old (24\%). About $20 \%$ of respondents came from age 60 - 69 years old, $12 \%$ from age 70 years old and more, $10 \%$ from age 30 - 39 years old and $6 \%$ from age $18-29$ years old. Most of the respondents with $42 \%$ of them had at least primary education attainment. There were $36 \%$ of respondents with at least secondary education attainment, $15 \%$ with no formal education, $6 \%$ with tertiary education attainment and $1 \%$ were education unclassified.

\section{Reading medication label}

Out of 3851 total respondents who had diabetes, 2881 respondents reported they read their medication label when received or purchased it. The prevalence of diabetes patients who read medication label every time received or bought medicines was $75.3 \%$ (95\% Cl 73.8-76.6\%) while $19.9 \%$ (95\% Cl 18.6-21.2\%) did not read the label every time when received or bought medicines and $4.8 \%(95 \%$ $\mathrm{Cl} 4.1-5.6 \%)$ of the respondents refuse to answer.

The results shows males $81.4 \%$, (95\%C.I: $79.5-83.2)$ and urban dwellers $77.5 \%(95 \%$ C.I: 75.8-79.2), reported higher prevalence in reading medication label. Respondents with tertiary education level reported higher prevalence in reading medication label. Within the age group, the highest prevalence was reported among those aged 30-39 years while the lowest prevalence was reported among those aged group 70 years and above. Malays $(\mathrm{N}=2199)$ were significantly higher in prevalence of reading medication labels $79.8 \%$ (95\% Cl 78.1-81.4), followed by Indians $(\mathrm{N}=556) 75.3 \%(95 \%$ Cl 71.5-78.7), others ( $\mathrm{N}=76) 73.7 \%(95 \% \mathrm{Cl} 62.8-82.4)$, other Bumiputeras $(\mathrm{N}=230) 67.1 \%(95 \% \mathrm{Cl} 60.7-72.9)$ and Chinese $(\mathrm{N}=790) 65.7 \%$ (95\% Cl 62.3-68.9).

\section{Types of information being read}

The most frequently read information reported by the respondents was dosage; (46.40\%), followed by method of administration; (42.20\%) and frequency of intake (40.80\%). The least being read was the purpose; (30\%), followed by name of medicine; (26.7\%), expiry date; (20.2\%), storage conditions; (3.9\%) and registration number (0.9\%). Only eight respondents were found to read all the eight types of information on the medication label.

\section{Understanding medication labeling}

Table 1 Among 2881 respondents who read medication label, 97.1\%, (95\%C.I: 96.4-97.7) claimed they understood the medication label information. Respondent who claimed did not understand medication labels were those without formal education, 7.9\% (95\%C.I: 4.8-12.9) followed by primary education, $3.7 \%$ (95\%C.I: 2.7-5.0), secondary education, $1.9 \%$ (95\%C.I: $1.3-2.8$ ) and tertiary education, $0.8 \%$

Table 1. Factors associated with not understanding medication labeling on univariate analysis (crude odds ratio) and multiple logistic regression (adjusted odds ratio)

\begin{tabular}{|c|c|c|c|c|c|}
\hline $\begin{array}{l}\text { Socio Demographic } \\
\text { Characteristics }\end{array}$ & Category & cOR & $95 \% \mathrm{CI}$ & aOR & 95\% CI \\
\hline \multirow[t]{2}{*}{ Gender } & Male & 0.86 & $0.56-1.32$ & 1.06 & $0.67-1.67$ \\
\hline & Female & 1.00 & - & - & - \\
\hline \multirow[t]{2}{*}{ Residence } & Urban & 1.00 & - & - & - \\
\hline & Rural & 1.45 & $0.94-2.24$ & 1.24 & $0.77-1.99$ \\
\hline \multirow[t]{6}{*}{ Race } & Malay & 1.00 & - & - & - \\
\hline & Chinese & 1.14 & $0.67-1.93$ & 1.10 & $0.63-1.94$ \\
\hline & Indian & 0.50 & $0.23-1.11$ & 0.53 & $0.24-1.19$ \\
\hline & Other & & & & \\
\hline & Bumis & 0.19 & $0.03-1.40$ & 0.45 & $0.06-3.44$ \\
\hline & Others & 0.55 & $0.07-4.01$ & 0.16 & $0.22-1.16$ \\
\hline \multirow[t]{6}{*}{ Age Group } & $18-29$ & 1.30 & $0.41-4.15$ & 1.40 & $0.44-1.53$ \\
\hline & $30-39$ & 1.00 & - & - & - \\
\hline & $40-49$ & 1.54 & $0.65-3.61$ & 1.18 & $0.49-2.83$ \\
\hline & $50-59$ & 1.64 & $0.72-3.76$ & 1.04 & $0.46-2.52$ \\
\hline & $60-69$ & 1.41 & $0.56-3.58$ & 0.70 & $0.26-1.86$ \\
\hline & $\begin{array}{l}70 \text { and } \\
\text { above }\end{array}$ & 2.15 & $0.71-6.52$ & 1.01 & $0.31-3.24$ \\
\hline \multirow[t]{4}{*}{ Education level } & $\begin{array}{l}\text { No formal } \\
\text { education }\end{array}$ & 10.39 & $2.33-46.34$ & 12.85 & $2.71-60.99$ \\
\hline & Primary & 4.58 & $1.10-19.02$ & 4.87 & $1.13-20.89$ \\
\hline & Secondary & 2.33 & $0.55-9.94$ & 2.41 & $0.56-10.35$ \\
\hline & Tertiary & 1.00 & - & - & - \\
\hline
\end{tabular}


(95\%C.I: 0.2-3.3).

Those without formal education ( $\mathrm{aOR}=12.85, \mathrm{C} . \mathrm{I}: 2.71-60.99$ ) and primary education level ( $\mathrm{aOR}=4.87, \mathrm{C} . \mathrm{I}: 1.13-20.89$ ) were significantly associated with not understanding medication labeling by the multiple logistic regression analysis after adjusting all the other predictors. Although the elderly aged 70 years and above reported the highest prevalence of not understanding the medication label, 4.3\% (95\%C.l; 1.9-9.3), it did not showed any significant association by multivariate analysis. There was no other significant association with the rest of variables.

\section{Ask for clarification}

Most diabetic (86.8\%) clarified their medications from the dispenser regarding 8 types of information that include registration number, name of medicine, purpose of using medicine, dose or measurement should be taken, frequency of intake, how to take or use, expired date and also storage condition. More males, $87.9 \%$ (95\%C.I: $86.3-89.3$ ) than females, $85.9 \%$ (95\%C.I: 84.4-87.4) sought clarification about their medications, but this is not significantly different.

Most of respondents with tertiary education, $91.1 \%$ (95\%C.I: 86.8-94.1) sought clarification about their medicines. Diabetic respondents with no formal education reported the highest prevalence of did not asked for clarification, $14.7 \%$ (95\%C.I: 1.7-2.6) followed by primary education, $12.4 \%$ (95\%C.I:10.8-14.1), secondary education, $11.2 \%$ (95\%C.I: 9.713.0) and tertiary education $8.9 \%$ (95\%C.I:5.9-13.2).

In term of age group, those aged 70 years and above have the highest prevalence for did not ask for clarification, $16.0 \%$ (95\% Cl; 12.4-20.4).

It was found that $90.1 \%$ of respondents who claimed understood medication label, they tend to elucidate their medicines from the dispenser. However the prevalence of respondents who did not understand medication label and did not sought clarification at all from the dispenser was $28.7 \%$.

\section{Discussion}

The proper reading on medication labeling is an important part of disease management. While the majority (75.3\%) of the respondents claimed they read medication labels, it was not a common practice among a sizable number of diabetes respondents (19.9\%).Chinese was significantly lower in prevalence of reading medication labels in comparison to other major ethnic in Malaysia. The National Survey on the Use of Medicines (NSUM), conducted in 2008 reported similar finding whereby only $78.2 \%$ of the Chinese read the medication label before taking their medicines, in comparison to Indians (83.0\%), Malays (91.8\%) and other ethnic group (92.5\%) [13].

Respondents without formal education were significantly lower in prevalence of reading medication label thus undoubted the highest prevalence for not understanding the medication label. A similar study showed that those with low education level had the tendency to misunderstand prescribed drug warning label $[18,19]$.

Elderly showed lower prevalence in reading medication label and this result was supported by Zucollo and Lindel's study that $60 \%$ of the elderly respondents had problems reading the medication labels [17]. After adjusting all predictors in multivariate analysis, it was found that there was no association between elderly and understanding of medication label and this result was contradicted to other literatures. As pointed out by several studies, medication labels can be confusing to the elderly people and this lead to the misunderstanding of the labels $[18,20]$. Another study found that $67.0 \%$ of elderly persons did not fully understand the medication labels [9]. This was supported by other study which showed that older adults were less able to comprehend medication labels as compared to younger adults [21].

Medication labels contain important information to ensure patients' safe use of medication [16]. WThe US Food and Drug Administration (FDA) has revised the labeling standards on June 2006 to ensure patients' understanding of appropriate prescription drug use [30]. Accordingly, the medication label must state name of drug, pharmacy, prescribing physician, patient's name as well as instructions for use. Although all information was deemed important, the respondents tend to read particularly the dosage followed by method of administration and frequency of intake. This finding was corroborated by a study done by Nabors et al. whereby most high school and college students tend to read information about dosage instructions and ingredients in comparison to other kind of information [1]. Many studies have documented that a large number of patients especially those with lower literacy have problems understanding even simple instruction on medication label $[33,31,18]$. Study by Michael S. Wolf found that the ability to read dosage instructions did not always preclude the ability to demonstrate a functional understanding of prescription drug use; $46 \%$ of patients misunderstood one or more dosage instruction. The prevalence of misunderstanding among patients with adequate, marginal and low literacy was $38 \%, 51 \%$ and $63 \%$ respectively $(p<0.001)$. Patients with low literacy were less able to state the correct number of pills taken daily compared to those with marginal and adequate literacy [31].

This situation where respondents did not read medication label every time received or bought medicine and lower in prevalence of reading medication labeling should not happen since diabetes is one of major chronic disease that requires continuous medical care and patient selfmanagement including monitoring and maintaining good glycemic control towards preventing acute complication and reducing the risk of long term complication $[14,15]$. Study from Schillinger et al. concluded that there is an association between low literacy among diabetes patients with a poor diabetes outcomes as measured by $\mathrm{HA}_{1 c}$ levels 
and they were also reported to have retinopathy [34]. Similar findings were reported where low health literacy has significant relationship with poor blood pressure and glycemic control. All these findings showed that poor health literacy includes obtain, process and understand is associated to poor health outcomes [11].

Pharmacist play an important role in helping patients to get the most benefits from the medication by explaining illness and the treatment. Pharmacist can help by explaining how medicines work and the importance of taking them properly, giving advice and guidance to clarify and explain information on packs and in leaflets, advising on which over-the counter (OTC) are suitable to treat minor ailments for patients taking prescription medicines and advising people about common side-effect and what they mean to their health. Based on this study, it was found that $12 \%$ of all respondents never sought clarification from the pharmacist about their medicines. Since elderly and no formal education were the most who reported did not understand the medication label, therefore it was expected that they sought clarification from the pharmacist regarding their medicine. However, these two groups were also reported to have the highest prevalence of never sought clarification from the pharmacists. Never sought and lack of clarification from the pharmacist might lead to medication errors and adverse events, as respondents may unintentionally misuse a prescribed medicine due to improper understanding of instructions. An overview by Ruth Parker showed that there are multiple reasons associated with those with low health literacy level. Among these were limited health vocabulary, limited background of health knowledge ,physician's facile use of medical term, and trouble assimilating new information and concepts as well as physicians' dependence on a health related brochure than explaining to the patients themselves [22]. To improve diabetic side-management behaviors, health care providers should improve their relationship with patients and they play an important role in improving patients' knowledge about their disease and the benefits of reading medication label [29,32].

More emphasis should be given to elderly and those without formal education who has lower degree of literacy. Consequently, a proper and interesting presentation of medication label could be designed to ensure that the information is readable, comprehensible, which can aid in reducing medication errors and further ensuring medication safety among diabetes patients [23-27]. Pharmacist and general practitioners should take time to explain more about the medicines and its side effect especially for those who did not read and not able to understand the medication label [28].

\section{Limitation}

This study utilized secondary data from the NHMS 2006 study. The analysis presented was able to provide a general picture regarding medical labeling literacy towards general medication. However the findings cannot represent situation among diabetics as respondents were not sampled to represent diabetics in Malaysia. A future study can be conducted in hospitals for the targeted group.

\section{Conclusion}

The findings showed an angle of health disparity across socio demographic parameter among Malaysian diabetic. Therefore, efforts should be made towards improving medication label literacy among diabetes patients because it is essential for them to fully understand their medicines. Continuous awareness and education campaign and strategy towards understanding medication labeling need to be carried out.

\section{Competing interests}

The authors declare that they have no competing interests.

\section{Authors' contributions}

NS: Set the objective, study design, analysis and interpretation of the data, and drafted the manuscript. SZM: Involve in study design and drafted the manuscript. RS: Involve in study design and drafted the manuscript. $B M N$ : Involve in data analysis and drafted the manuscript. HAAH: Involve in drafted and edited the manuscript. HM: Involve in drafted and edited the manuscript.

Acknowledgement

The authors would like to thank the Director General of Health Malaysia, for his permission to publish this paper.

Publication history

Received: 6-Nov-2012 Revised: 12-Dec-2012

Accepted: 13-Dec-2012 Published: 26-Dec-2012

\section{References}

1. Nabors LA, LehmkuhI HD, Parkins IS and Drury AM: Reading about over-the-counter medications. Issues Compr Pediatr Nurs 2004, 27:297-305. | Article | PubMed

2. Ishikawa $\mathrm{H}$ and Yano $\mathrm{E}$ : Patient health literacy and participation in the health-care process. Health Expect 2008, 11:113-22. | Article | PubMed

3. Kickbusch IS: Health literacy: addressing the health and education divide. Health Promot Int 2001, 16:289-97. | Article | PubMed

4. Adult Literacy and Life Skills Survey :Summary Results. Australia. | Link

5. Kirsch I JA, Jenkins L: Adult Literacy in America: A First Look at the Results of the National Adult Literacy Survey 1993. | Article

6. Health Literacy: A Prescription to End Confusion. I Link

7. Kutner MG, Elizabeth; Baer, Justin. A: First Look at the Literacy of America's Adults in the 21st Century. National Center for Education Statistics 2006, 470. | PDF

8. Institute For Public Health, Ministry of Health Malaysia :The third National Health And Morbidity Survey 2006 (NHMS III).

9. Moisan J, Gaudet M, Gregoire JP and Bouchard R: Non-compliance with drug treatment and reading difficulties with regard to prescription labelling among seniors. Gerontology 2002, 48:44-51. | Article | PubMed

10. Gazmararian JA, Williams MV, Peel J and Baker DW: Health literacy and knowledge of chronic disease. Patient Educ Couns 2003, 51:267-75. I Article | PubMed

11. Williams MV, Baker DW, Parker RM and Nurss JR: Relationship of functional health literacy to patients' knowledge of their chronic disease. A study of patients with hypertension and diabetes. Arch Intern Med 1998, 158:166-72. | Article | PubMed

12. Schillinger D, Barton LR, Karter AJ, Wang F and Adler N: Does literacy mediate the relationship between education and health outcomes? A study of a low-income population with diabetes. Public Health Rep 
Norhafizah et al. Journal of Diabetes Research \& Clinical Metabolism 2012, http://www.hoajonline.com/journals/pdf/2050-0866-1-23.pdf

2006, 121:245-54. | PubMed Abstract | PubMed Full Text

13. Pharmaceutical Services Division MoHM :A National Survey On The Use Of Medicine (NSUM) By Malaysian Consumers 2008.

14. Vredenburgh AG and Zackowitz IB: Drug labeling and its impact on patient safety. Work 2009, 33:169-74. | Article | PubMed

15. Odegard PS and Gray SL: Barriers to medication adherence in poorly controlled diabetes mellitus. Diabetes Educ 2008, 34:692-7. | Article | PubMed

16. Safe use of medicine. | Link

17. Zuccollo $\mathrm{G}$ and Liddell $\mathrm{H}$ : The elderly and the medication label: doing it better. Age Ageing 1985, 14:371-6. | Article | PubMed

18. Davis TC, Wolf MS, Bass PF, 3rd, Thompson JA, Tilson HH, Neuberger M and Parker RM: Literacy and misunderstanding prescription drug labels. Ann Intern Med 2006, 145:887-94. I PubMed

19. Shrank WH, Agnew-Blais J, Choudhry NK, Wolf MS, Kesselheim AS, Avorn $J$ and Shekelle P: The variability and quality of medication container labels. Arch Intern Med 2007, 167:1760-5. | Article | PubMed

20. Davis TC, Wolf MS, Bass PF, 3rd, Middlebrooks M, Kennen E, Baker DW, Bennett CL, Durazo-Arvizu R, Bocchini A, Savory S and Parker RM: Low literacy impairs comprehension of prescription drug warning labels. $J$ Gen Intern Med 2006, 21:847-51. | Article | PubMed Abstract | PubMed Full Text

21. Morrell RW, Park DC and Poon LW: Effects of labeling techniques on memory and comprehension of prescription information in young and old adults. J Gerontol 1990, 45:P166-72. | Article | PubMed

22. Roter DL, Erby LH, Larson S and Ellington L: Assessing oral literacy demand in genetic counseling dialogue: preliminary test of a conceptual framework. Soc Sci Med 2007, 65:1442-57. | Article | PubMed Abstract | PubMed Full Text

23. Forbis SG and Aligne CA: Poor readability of written asthma management plans found in national guidelines. Pediatrics 2002, 109:e52. | Article | PubMed

24. Davis TC, Federman AD, Bass PF, 3rd, Jackson RH, Middlebrooks $\mathrm{M}$, Parker RM and Wolf MS: Improving patient understanding of prescription drug label instructions. J Gen Intern Med 2009, 24:57-62. | Article | PubMed Abstract | PubMed Full Text

25. Katz MG, Kripalani S and Weiss BD: Use of pictorial aids in medication instructions: a review of the literature. Am J Health Syst Pharm 2006, 63:2391-7. | Article | PubMed

26. Villaire $M$ and Mayer $G$ : Low health literacy: the impact on chronic illness management. Prof Case Manag 2007, 12:213-6; quiz 217-8. | PubMed

27. Stableford S and Mettger W: Plain language: a strategic response to the health literacy challenge. J Public Health Policy 2007, 28:71-93. | Article I PubMed

28. Ishikawa $\mathrm{H}$ and Kiuchi T: Health literacy and health communication. Biopsychosoc Med 2010, 4:18. | Article | PubMed Abstract | PubMed Full Text

29. Vermeire E, Hearnshaw H, Ratsep A, Levasseur G, Petek D, van Dam $H$, van der Horst F, Vinter-Repalust N, Wens J, Dale J and Van Royen P: Obstacles to adherence in living with type-2 diabetes: an international qualitative study using meta-ethnography (EUROBSTACLE). Prim Care Diabetes 2007, 1:25-33. | Article | PubMed

30. The American College of Physicians Foundation (ACPF): Improving prescription drug container labeling in the United States. A Health Literacy and Medication Safety Initiative. Institute of Medicine Roundtable on Health Literacy, Washington, DC; 2007. | PDF

31. Wolf MS, Davis TC, Shrank W, Rapp DN, Bass PF, Connor UM, Clayman $\mathrm{M}$ and Parker RM: To err is human: patient misinterpretations of prescription drug label instructions. Patient Educ Couns 2007, 67:293300. | Article | PubMed

32. Al-Qazaz HK, Hassali MA, Shafie AA, Syed Sulaiman SA and Sundram S: Perception and knowledge of patients with type 2 diabetes in Malaysia about their disease and medication: a qualitative study. Res Social Adm Pharm 2011, 7:180-91. | Article | PubMed

33. Wolf MS, Davis TC, Bass PF, Curtis LM, Lindquist LA, Webb JA, Bocchini MV, Bailey SC and Parker RM: Improving prescription drug warnings to promote patient comprehension. Arch Intern Med 2010, 170:50-6. | Article | PubMed

34. Schillinger D, Grumbach K, Piette J, Wang F, Osmond D, Daher C, Palacios $J$, Sullivan GD and Bindman AB: Association of health literacy with diabetes outcomes. JAMA 2002, 288:475-82. | Article | PubMed 